\title{
Molecular and Physiological Determinants of Pulmonary Developmental Biology: a Review
}

\author{
Asima Hameed $^{1,2}$, Muhammad Azhar Sherkheli ${ }^{1, *}$, Abrar Hussain ${ }^{3}$, Rizwan Ul-haq ${ }^{1}$ \\ ${ }^{1}$ Department of Pharmacy, Hazara University, Havelian Campus, Abbottabad, Pakistan \\ ${ }^{2}$ Punjab Institute of Cardiology, Lahore, Pakistan \\ ${ }^{3}$ Centre of Excellence in Molecular Biology, University of the Punjab, Lahore, Pakistan \\ *Corresponding author: azhar.sherkheli@daad-alumni.de
}

Received January 26, 2013; Revised February 02, 2013; Accepted February 28, 2013

\begin{abstract}
The lungs undergo an extensive endodermal diverging morphogenesis along with alveogenesis, angiogenesis, and vasculogenesis to secure a sufficient diffusion surface for gaseous exchange. Any aberration in the course of normal development inculcating structural and functional abnormalities of lungs in antenatal life has potential morbidity in adult life. Factors such as IUGR, nutrient deficiency, FLM, Hypoxemia, ETS, surfactant deficiency, allergy and infections can adversely affect in-utero lungs development. Peculiar local and systemic inflammatory immune responses may elicit persistent architectural and physiological abnormalities. Lung surfactant produced by AEC-II cells is a mixture of phospholipids, surfactant proteins, and neutral lipids. Surfactant lowers alveolar surface tension, a crucial step for the prevention of alveolar collapse. Surfactant proteins are part of the innate immune defense of the lung. Surfactant deficiency and dysfunction is known to implicate a number of respiratory diseases especially allergic asthma and NRDS. The present article provides a state of the art review of the current knowledge of biology of normal lung development, its anatomical and molecular aspects, factors that regulate normal organogenesis of pulmonary system and molecular basis of respiratory allergic disorders including asthma.
\end{abstract}

Keywords: respiratory diseases, allergic disorders, pulmonary development, lung surfactants

\section{Introduction}

In depth understanding of pulmonary developmental biology has profound and substantial impact on human health outcomes. Lungs are the sole organ, exclusively performing the function of exchange of gases to enable an organism to acclimatize to terrestrial life. Any malfunctioning in the conversion of this fluid filled organ, apparently unimportant to intrauterine survival, into air filled hollow structure endangers perinatal survival. Respiratory disorders in early life stages contribute to major morbidity and mortality causes the world over [1]. Despite the fact that normal adult lungs can undergo repair, it is seen that prenatal deficits cannot be resolved in perinatal life resulting in morbidity and clinical burdens [2]. Understanding of lungs developmental biology holds the key which could be used to aid lungs-repair and regeneration.

Various studies on human and animal models have shown that the development and later function of lungs can be influenced by in-utero environmental compromises (including physical, endocrine, maternal tobacco smoking during pregnancy, maternal diabetes, metabolic disturbances and reduced amniotic fluid volume and inflammatory factors [3] during fetal and early postnatal life [4]. These factors are not limited to individual responses; in fact abnormality of one component can alter the reaction of others. Moreover a number of early life factors including atopy, lower respiratory infections, low SES, active and passive smoking during childhood and nutrition are also shown to be associated with disturbed pulmonary function over whole life span $[5,6,7,8,9,10,11,12]$. Many of the factors that affect fetal growth cause intrauterine growth restriction (IUGR) causing preterm birth $(\mathrm{PB})$ and low birth weight. Numerous epidemiological studies have indicated that low birth weight is associated with an increased risk of respiratory symptoms or illnesses after birth [4].

Most of the studies investigating developmental paradigm of lungs are done on animal models having very different timing of morphological growth stages compared with humans. The animals mostly subjected to such studies include Drosophila, rabbits, sheep, rats and mice. The most useful information is mined from research work done in rats and mice as most of their alveolar development occurs postnatally like that of humans. The research conducted on animal models has abetted to identify potential and actual fetal and neonatal pulmonary disorders and their solutions to alleviate neonatal morbidity and mortality [13].

The present article provides a concise review on the current knowledge of biology of normal lung development, its anatomical and molecular aspects and factors that regulates normal organogenesis of pulmonary system. A brief overview of developmental anomalies and acquired pathologies is included, outlined with experimental and 
epidemiological evidences showing that the exposure to certain factors, precarious to fetal and neonatal lung can cause detrimental effects on lung architecture and physiology, can result in persistent alterations in respiratory function. The effort is done to provide a separate and summarized discussion on development of lung surfactants system and immunity, effect of allergen exposure on surfactants-system of developing respiratory system in antenatal and postnatal life and its detrimental outcomes.

\section{Methods}

This review extracts the information from peerreviewed English-language publications and research articles identified from MEDLINE/PubMed, Tylor and Francis online, Science Direct, Wiley Interscience, and Elsevier data bases up to the year 2012. Search strategy was use of keywords along with various combinations of developmental biology, pulmonary system, growth factors, environmental exposure anomalies, allergies and lung surfactants. The PubMed function of "related articles" was used to get relevant articles not accessed from initial searches. Other searches were carried out by using names of authors of relevant articles. The original articles from review material were accessed through references where possible. The tables in this review are limited to studies that provide the basic understanding and pathology of stated diseases. The discussion and material in this review is restricted to most investigated and accepted knowledge in the concerned field.

\section{Development of Respiratory System}

\subsection{Programming and Growth}

In humans and some other mammals who have longgestation periods, development of the pulmonary architecture is an ongoing process till early postnatal life [14]. The lung mostly comprises of two highly branched tubular systems 'the airways and the vasculature' working in conjunction to efficiently perform the gas exchange. As the most critical time of birth reaches, the airways are formed and terminal air sacs mainly function as prototypes of definitive alveoli. Alveolar formation continues till 1836 months of postnatal life [15]. Later lung growth largely occurs by the enlargement of existing alveoli (see Figure 1).

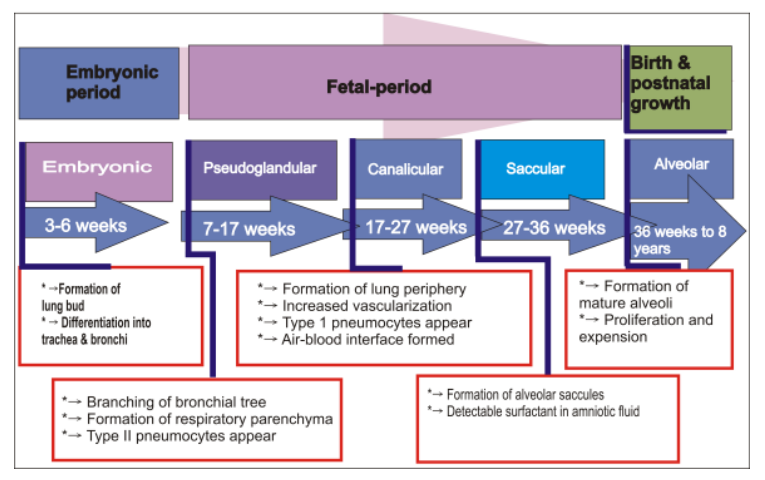

Figure 1. Summary of various stages and structural organizations in the development of lungs in prenatal and postnatal life
The four major levels of development are recognized, first of which is Embryogenesis (the progress of fertilized ovum to an embryo). Second is Morphogenesis involving tissue complexion and maturation and starts from formation of main frame of pulmonary system to development of specialized gas exchange surfaces (alveoli). During the third level, Differentiation of specialized cells (alveolar type-II cells) from precursor cells occur $[16,17,18,19]$. The Growth includes Volume expansion which starts in prenatal stage [20] and extends to postnatal life [21]. Factors controlling lung growth during these phases are reviewed later in this article.

The formation of primary germ layers, the ectoderm, the mesoderm and the endoderm occurs during gastrulation period. The endoderm then undergoes morphogenesis orchestrating to form primitive gut tube [22]. The broad gene expression patterns, in precise domains of fore, mid and hindgut regulates development of specific organs. The endodermal patterning is also controlled by conjoint interactions with surrounding mesodermal tissue [22].

The development of respiratory tract starts as a ventral out pouching from foregut called laryngotracheal groove, at fourth week of gestation [23]. The margins of this groove fuse to form laryngotracheal tube which grows caudally into splanchnic mesoderm forming right and left lung buds. These lung buds further divides to form an analog for main bronchi. In the mesenchyme of the laryngotracheal tube, cartilage develops with conversion of upper part of tube with larynx and lower part with trachea. Each bronchus then continues to subdivide laterally in a dichotomous way till terminal bronchioles and alveoli are formed. The pattern of branching is highly stereotyped and can be categorized in three sequences called "domain branching", "planar branching", "orthogonal bifurcation" depending on the plane along which branching occurs [24].

Lobes of lungs are formed by fifth week while bronchi keep on dividing in 6th week of gestation. This branching results in formation of bilobed left and trilobed right lung. The branching pattern is highly influenced by neighboring mesenchyme [25,26,27], various growth factors and epithelial-mesenchymal interactions and their dependence on maturity of type II alveolar cells [28,29,30,31,32].

\subsubsection{Pseudoglandular Phase}

Classically, the prenatal developmental phase of lung is described by distinct histological characters on basis of which different stages are [33,34,35,36,37] recognized. This phase extends from 7 to 17 th Week (see Figure 1). The main frame of pulmonary system is formed including bronchial tissue, cartilage, ciliated epithelium and scarce capillaries. The branching from bronchial buds and preacinar structures complete by 17 th week. Airways terminate blindly with columnar or cuboidal epithelium, yet alveoli are not formed [38]. By 3 months of gestation, lungs are of definitive shape.

\subsubsection{Canalicular Phase}

From 17 weeks to 27 weeks of gestation, Canalicular Phase continues in which development of bronchioles, alveolar ducts, primary acini and increased vascularization is involved. The epithelial cells' glycogen diminishes from 20th week. Type I and II pneumocytes are 
identifiable by 24 weeks of intra uterine life and Lamellar bodies containing surfactant proteins and phospholipid can be seen [39]. The first air-blood interface develops by the end of this stage $[35,36,37]$ in form of cylindrical saccules (in intermediate saccular stage) divided by crests known as secondary septae made of collagen and elastin [23].

\subsubsection{Alveolar Phase}

The next phase of respiratory system development called Alveolar phase (28 weeks to term: see Figure 1) is characterized by rapid growth and maturation of acini with remodeling of the double capillary layer and thinning of the alveolar walls, mesenchymal proliferation, and distinct increase in well differentiated type I and II pneumocytes [40].

The mature respiratory epithelium develops a diversity of cell types including ciliated, goblet, basal, Clara cells, pulmonary and alveolar macrophages. These Epithelial cell lineages are organized distally in airways. The Squamous epithelium lines larynx, upper airways are lined with ciliated columnar and mucus secreting cells while Clara cell lines lower respiratory tract. Small foci in epithelial cells of upper airways contain PNE cells (pulmonary endocrine cells). The Pulmonary interstitium also contain mesenchyme derived cell lineages like fibroblasts, myofibroblasts and smooth muscles. The Vascular set up includes endothelial cells and vessel wall smooth muscles of arteries, veins and capillaries along with lymphatic endothelial cells for lymphatic system [41]. Fetal lung is filled with liquid which prevents airways and developing alveoli from collapse. The liquid secretion of fetal lung is controlled by active secretion of chloride ion from pulmonary epithelium, which carries positive sodium and water along with it [42]. The production of lung liquid ceases under influence of adrenaline [43] as the term approaches.

As the fetus prepares to take its first breath, transition from intrauterine environment to extra-uterine life is an important challenge that respiratory system has to face. To make a successful adaptation, biochemical maturation of specialized enzyme system is also critical. Any immaturity of main biochemical systems (surfactants, antioxidant enzymes and lung liquid secretion) can contribute subsequent pathology of respiratory disorder particularly in preterm infants. Hyperoxia can cause production of free radicals hence damage endothelial cells and epithelial lining of lungs. The protective mechanisms include antioxidant enzymes and Vitamin A, C and E. The enzymes which provide defense against free radicals include catalase, glutathione peroxidase and superoxide dismutase. These systems mature as the gestation proceeds [44].

\section{Molecular Basics of Pulmonary Development}

The major challenge for researchers in understanding lung development is to trace the actual mechanisms that control the highly sophisticated orchestration from an outgrowth of endodermal foregut to a highly specialized organ. An insight to these mechanisms is important to find clues of genetic mutations, adverse effects associated with environmental toxins, drugs and intra-uterine infections that develop anomalies and help in designing solutions to improve developmental outcome.

The study of highly refined and systematically assimilated cellular and molecular mechanisms of development in human fetus is practically and ethically challenging to perform. Though some researches provide such intervention studies, the main contribution of knowledge and understanding comes from detailed study of molecular mechanisms of pulmonary development in animal models of Drosophila, mouse and sheep [41,45,46].

The process of lung development during endodermal organogenesis is controlled by a variety of multiple stage specific growth regulators including BMP, Wnt, Hedgehog factor, RA (retinoic acid) and Notch, Fibroblast growth factor-8 (FGF-8), Keratinocyte growth factor-7 (FGF-7), Platelet derived growth factor B, Epidermal growth factor, Insulin-like growth factor, Transforming growth factor, Vascular endothelial growth factor, Platelet derived growth factor (A) and Granulocyte macrophagecolony stimulating factor. Amazingly similar growth factors and signaling pathways are utilized during different growth stages but the impression produced varies depending on the phase. Some transcription factors such as Hhex, Cdx, Foxa2 have diversity of roles in forming regional identity and later Organogenesis [47]. Foxa2, which is selectively expressed in respiratory epithelium is also known to regulate Th-2 mediated innate defense and inflammation in developing lungs [48].

Table 1. Summary of various growth and transcription factors expressed in different phases of lung development

\begin{tabular}{|c|c|}
\hline \multicolumn{2}{|c|}{ Roles of Certain Mediators in Embryonic Development } \\
\hline $\begin{array}{c}\text { Phases of lungs } \\
\text { development }\end{array}$ & Growth/transcription factors involved \\
\hline $\begin{array}{l}\text { Formation of Lung } \\
\text { Primordium }\end{array}$ & FOXA 1/2, GATA 4/6, Gli, Tbx4 \\
\hline Tracheal Morphogenesis & Gli, HNF-3beta, RA, Tbx 4, FGFs \\
\hline $\begin{array}{l}\text { Branching, Differentiation } \\
\text { and control }\end{array}$ & $\begin{array}{l}\text { FGF-10, Tbx4/5, Gli, Nkx 2.1, GATA, } \\
\text { BMP-4, Shh, HOX genes }\end{array}$ \\
\hline Alveogenesis & $\begin{array}{l}\text { Nkx 2.1, GATA, BMP-4, Shh, FGF-10, } \\
\text { PDGF, IGF, RA }\end{array}$ \\
\hline $\begin{array}{l}\text { Surfactant induction and } \\
\text { regulation }\end{array}$ & FGFs, Nkx 2.1 \\
\hline $\begin{array}{l}\text { Vascular growth and } \\
\text { angiogenesis }\end{array}$ & $\begin{array}{l}\text { VEGF, EMAP II, Extracellular matrix } \\
\text { proteins, Cell adhesion receptors }\end{array}$ \\
\hline
\end{tabular}

The cellular initiation of lung organogenesis starts as result of increased FGF and Wnt signals from mesoderm, establishing localized domain of Nkx2-1 gene expression setting a mark for future trachea. Lung bud arises by a localized expression of Fgf10 for which RA and Hedgehog signaling is required to suppress TGF $\beta$ signaling that promotes the expression of $\mathrm{Tbx} 4 / 5$ and Hoxa4/5 as well as FGF10 [49,50]. The growing lung bud experiences a highly categorized branching to generate a highly integrated tree-like structure of the lung. Experimental evidences prove that a fine balance of collaborations between positive regulatory signals FGF10 and $\mathrm{Tbx} 4 / 5$ in the mesenchymal distal tip with negative feedback modulators Shh, BMP4, Fgfr2, and the FGFantagonist sprout in the growing distal tip epithelium, and this balance regulates branching pattern and equilibrium $[50,51]$. 
The epithelium of developing saccules differentiate to form various cell types among which AEC-1 (alveolar epithelial cell) that express aquaporin 5 and T1-alpha on maturation, and AEC-2 which secrete surfactant proteins and lipids when mature, are included. Crest formation and alveolar maturation requires elastin and myofibril [52]. Regulation of vascular and mesenchymal components involved in alveolization is governed by multiple signaling pathways and intercellular interactions including Pdgf-alpha, ephrin B2, Fgf and RA. The Fgf-2 and Fgf-18 are important for late stage lung development [53].

The ongoing research in embryology has shown importance of interactions in endodermal epithelium and splanchnic-mesodermal-mesenchyme growth, morphogenesis and cell differentiation in developing lungs. These epithelial mesenchymal interactions consequently are regulated by key signaling mediators as, FGF and their receptors, Wnt genes and $\beta$ - catenin, BMP4, sonic hedgehog and Gli genes [54].

In early stages of pulmonary development, multipotent epithelial cells differentiate to form pulmonary neuroendocrine cells under influence of MASH-1. The differentiation of these epithelial phenotypes also occurs under discrete transcriptional regulatory mechanisms. It is becoming clear that angiogenesis and vasculogenesis of the pulmonary circulation and capillary network are closely linked with each other and may be necessary for lung epithelial morphogenesis. The pulmonary vascularization involves a fine balance between positive angiogenic and vasculogenic factors (VEGF) [55,56,57], which signals through cognate receptors flk, flt $[57,58]$ and negative regulators (EMAP II) [57,59]. Growth factors, extraxcellular matrix proteins and cell adhesion receptors, all play important role in differentiation, commitment, and relocation of endothelial cells [60]. Research have shown that inhibition of VEGF cause cessation of vascular growth and altered epithelial proliferation but does not affect cell differentiation [61]. The detailed reviews on the cellular and molecular aspects of lung morphogenesis and development, done by various researchers $[21,27,45,50,62,63]$ can be consulted separately to obtain further insight in this aspect.

\section{Developmental Abnormalities of Respiratory System}

The normal pattern of developing pulmonary system can be disturbed by imbalance of various growth factors and genetic mutations or acquired pathology (infection, allergy, ETS) producing faulty gene expressions. In either case the result is in the form of structural and functional abnormality of lungs. Defect at each stage of development of the pulmonary tree can produce a different set of aberrations and hence pathological complications [64].

Abnormal developmental outcomes of embryonic stages may appear in the form of tracheo-oesophageal fistula, laryngeal, tracheal, or oesophageal atresia; tracheal stenosis; pulmonary agenesis or congenital lung cysts. Congenital anomalies like pulmonary hypoplasia, pulmonary sequestration, Lymphangectasia, Pulmonary adenomatoid malformation and Congenital diaphragmatic hernia (CHD) may evolve during the pseudoglandular stage. Pulmonary hypoplasia may also develop in canalicular phase, the underlying causes of which may be skeletal Dysplasias, Pleural space lesions, CNS damage, oligiohydramnios, or Congenital muscular disease $[13,29,38]$. The types of anomalies of pulmonary system alongwith reference of their detailed discussion on each disorder, its presentation, pathophysiology and factors contributing it are stated in Table 2.

Table 2. Developmental Anomalies of Respiratory Systema-d

\begin{tabular}{|lc|}
\hline Anatomical region & Anomaly \\
\hline Upper Respiratory & Anterior and posterior nares \\
\cline { 2 - 3 } & Clefts of lips and palate \\
\hline Lower Respiratory tract & \\
\hline Trachea & Laryngeal artesia \\
& Laryngeal Stenosis and Obstruction \\
& Laryngeal clefts \\
& Laryngeal Cysts \\
& Laryngomalacia \\
\hline Lungs & Tracheal agenesis \\
& Tracheal Stenosis \\
& Tracheoesophageal Fistula \\
Trachea-Bronchomalacia
\end{tabular}

a-d $[65,66,67,68]$

The respiratory disorders of newborn especially preterm birth may be due to acquired pathology occurring mainly through immaturity, infection, exposure to environmental toxins or birth asphyxia. These problems can manifest themselves in the form of Respiratory Distress Syndrome, Hyaline membrane disease, Bronchopulmonary dysplasia (Chronic Lung Disease), Pulmonary interstitial emphysema (PIE), Pulmonary hemorrhage, and Meconium aspiration syndrome [29].

Ascending infection may cause still birth or even spontaneous abortion mostly before 24 weeks of gestation. Infective organisms in case of ascending infection may be E. coli, GBS, Candida [69,70], Mycoplasma, Ureaplasma or Chlamydia in some cases [71,72,73].

The causative agents in case of viral infections include Herpes Simplex, Congenital Cytomegalovirus, RSV and Metapneumovirus. Herpes Simplex virus and Enteroviruses are known to be transmitted to neonate antenatelly or during passage through birth canal [74,75].

Bronchopulmonary dysplasia (BPD) and CLD are specifically perinatal disorders that occur in infants who are born preterm with some acute lung disease and receive intensive care therapies for respiratory assistance through Ventilators [76,78].

A single insufficiency of inadequate surfactant may culminate in increased work of breathing by raised vascular functional resistance, limiting residual capacity and decreasing alveolar ventilation, which in turn can give rise to Respiratory distress syndrome, Meconium aspiration syndrome, appearance of Pulmonary air-leak syndromes (pulmonary interstitial emphysema, subcutaneous 
emphysema, pneumomediastinum, pneumoperitoneum, pneumopericardium, pneumothorax) and transient tachypnea of the newborn in preterm infants.

\section{Factors Effecting Pulmonary Development}

The research over past few decades has provided a great insight regarding factors regulating the pulmonary development .But revealing the actual underlying mechanism can be challenging as well as promising to design manipulative strategies that may prevent and resolve fetal and neonatal morbidity and mortality.

The key physical factor regulating lung maturation is the stretch force exerted by luminal fluid which acts as a stent to maintain partially expanded lung $[79,80]$. The fetal lung liquid is developed from two main sources including secretions of epithelial cells themselves and amniotic fluid [81] Removing the stretch stimulus of luminal liquid causes simulated termination of fetal lung growth while over-distension leads rapid tissue growth and structural development, of the alveolar wall $[82,83]$. This stretch exerting factor in turn is controlled by transpulmonary pressure gradient and the resistance of the upper respiratory tract. Fetal lung movements also play major role in maintaining lung expansion to elicit a positive signal for lung growth [84].

An impaired nutrient supply proves to have damaging effect on antenatal and postnatal lung development $[85,86]$ The effects of malnutrition include compromised maturation of type 11 alveolar epithelial cells [87] causing decreased surfactant production and increased surface tension [88-89], reduction in lung weight and decreased DNA, protein and elastin content, an increase in lung to bodyweight ratio [90,91,92], decreased alveolar formation with underdeveloped air-blood boundary providing a reduced surface area for gaseous exchange and compromised action of acid phosphatase in alveolar macrophages, thus resulting in altered pulmonary resistance $[87,92,93,94,95,96]$. Lung function is also reduced in preterm infants however impact of $I U G R$ on later lung physiology is more pronounced in children born after $26^{\text {th }}$ gestational week [97].

Hypoxia can be established as sole factor to cause IUGR resulting in surfactant deficiency induced acute and chronic pulmonary disorders of developing lung $[98,99,100]$. Hypoxia inducible factors are key regulators for adaptation to hypoxic milieu throughout and after intrauterine life. HIF- $1 \alpha$ and HIF- $2 \alpha$ protein serve distinct and specific roles in vascular and epithelial morphogenesis [101,102]. Loss or insuffiency of HIF-2 $\alpha$ culminate in impaired pulmonary development, decreased surfactant production, ARDS and even neonatal death [103]. Prenatal and post natal exposure to glucocorticoids (betamethasone, dexamethasone and cortisol) have been demonstrated by various studies, to be helpful for epithelial cell maturation and improved amounts of pulmonary surfactant and suppressed inflammatory response[104,105,106,107]. Other elements that retard IUG include Chest wall anomalies, diaphragmatic hernia, Oligohydroamnios, Rhesus Isoimmunization, Renal anomalies, Myotonic Dystrophy, Anecephaly, Maternal diabetes, Alcohol and Nicotine, while sex hormones and several growth factors discussed in molecular mechanisms of lung growth are also known to affect fetal and neonatal lung development [23]. The IUGR in turn can result in low BW which is shown to have strong association with childhood asthma and respiratory indisposition and mortality [108-109].

\section{Allergy and Lungs}

\subsection{Developing Immune System of Respiratory Tract and Early Origins of Allergic Disorders}

The preservation of sterility at distal end of respiratory tract (alveoli) is very critical as exposure to pathogens from oral end of respiratory tract is a constant threat. This necessitates the importance of specialized immune set up in respiratory machinery. This combat infantry consists of innate immunity, mucus secretion, fluid and electrolyte transport and surfactant balance.

The immunological setup of lung includes both inflammatory and migratory cells responsible for immune response [110,111].These cells include Helper $\mathrm{T}$ cells $\left(\mathrm{T}_{\mathrm{H}} 1, \mathrm{~T}_{\mathrm{H}} 2\right)$, alveolar Macrophages, dendritic cells, basophils, and airway epithelial cells in lung. The distinct sets of growth factors control the fetal and perinatal maturation of the immune cells in respiratory system and play fundamental role in regulating immunological homeostasis. Any encounter of immature immune system of lungs with aeroallergens cause the development of allergen-specific immune memory through infant's $\mathrm{T}$ cell selection. These T-memory cells cause suppression of allergy predisposing, cytokine secreting $\mathrm{Th} 2$ cells via expressing Th1 pattern cytokines. Any exogenous or endogenous assault to this immunomodulatory process causes failure of Th-1 memory cells, predisposing the Th2 mediated allergic reactions. The evidences also propose that a fetus may be prone to allergy because of intrauterine hyperactivity of control mechanisms (Thurlbeck, 1982).

The tissue and organ seeding of lung by macrophages and dendritic cells, begins by 4-7 week of gestation with substantial development and reorganization in late first trimester and throughout the second trimester [112,113]. The IgE starts at 11 week of gestation in human fetus. By 21 weeks T-cell proliferation is seen when exposed to in vitro allergens. As the term approaches, IL-1, 4, 6, 7, 8 and TNF $\alpha$ and IFN $\gamma$ are detectable in amniotic fluid [110].

The respiratory allergens, pathogens, environmental and genetic risk factors for allergy and asthma, usually impede innate immunity in respiratory system through airway epithelial cells, DCs and basophiles [107] the epithelial cells form the first line of defense against allergens [114,115,116,117]. Members of transient receptor potential (TRP) super-family of cation channels $[118,119,120,121,122]$ play crucial role in the development of allergic disorders of pulmonary system and hence provide important therapeutic targets [123,124]. In addition to TRP ion channels, the importance of toll like receptors has been well established $[125,126,127,128,129,130]$ as component of innate immunity. Forexample, " $\mathrm{T}_{\mathrm{H}} 1$ cells" are the members of first combat force and provoke $\mathrm{T}_{\mathrm{H}} 2$-polarized immune memory of inhaled allergens. The research now focuses more on Th2 cell and eosinophilic inclination for immune 
response [131] as the Th1 and Th2 clones in lung mediate through different patterns of Cytokines [132,133]. Any encounter of immature immune system of lungs with aeroallergens cause the development of allergen-specific immune memory through infant's $T$ cell selection. These T-memory cells cause suppression of allergy predisposing, cytokine secreting Th2 cells via expressing Th1 pattern cytokines. Any exogenous or endogenous assault to this immunomodulatory process causes failure of Th1 memory cells, predisposing the Th2 mediated allergic reactions [134]. The Th2 based immune control inutero is known to produce high levels of Cytokines (IL-4, IL-13) and IgE while decreased levels of IFN $\gamma[135,136,137,138,139,140]$. The evidences also propose that a fetus may be prone to allergy because of intrauterine hyperactivity of control mechanisms [141]. The studies have shown that delayed maturation of $\mathrm{T}_{\mathrm{H}} 1$ in early infancy increase the susceptibility to acquire inflammation through aeroallergens which restricts lung growth and maturation [142].

The Dendritic cells (DCs) play a key role in regulating T helper 2 cell (Th2) immunity to aeroallergens. Different subsets of DCs (CD11b+ and CD11b- subsets) execute anti-inflammatory response by antigen uptake, draining to Lymph Nodes, and generation of adaptive immunity. The pulmonary epithelium (TLRs) not only acts as a physical barrier to allergens and pathogens but also switches release of cytokines which promote function of lung DCs and Th2 cells. The stimulation of epithelial cells by allergens also creates an immunological microenvironment involving immature DCs in defense cascade [143]. The alveolar macrophages specialize in triggering inflammatory reactions against pathogens, exposed to alveoli $[114,115]$.

Thus the Early-life immune insults (ELII) owing to allergy, Environmental toxins (air pollution, tobacco smoke), infections or developmental immunotoxicity (DIT) has been shown to culminate in several respiratory disorders most important of which is child hood and late asthma [144,145]. The allergen contact in pregnancy may also stimulate allergic responses in the neonate by presensitizing the fetus through transplacental exposure $[146,147,148]$.

\section{Lungs Surfactant System}

Since the initial recognition of surfactant role in lowering surface tension of lung $[149,150]$ a great has been laid on the study of its nature and functions. It is remarkable to note that this surfactant system also plays a vital role in pulmonary innate immune defense system against allergic threats [151]. A single abnormality of surfactant deficiency can manifest itself directly or indirectly in the form of multiple respiratory disorders of neonates including NRDS, CLD and AA [152,153]. Moreover, inflammatory enzymes produced as a result of allergen exposure or infection, can create surfactant deficiency by degrading it. This functional diversity of lung surfactants is tempting for a researcher because a complete insight to surfactant system has unique potential to resolve many problems of respiratory insufficiency in newborns especially preterm infants. A brief overview of composition, functions and importance of lung surfactant in terms of its immunomodulatory drive to fight allergens will be reviewed in this article.

\subsection{The Composition of Lung Surfactant}

As discussed earlier, AEC-II are involved in lung surfactant production. This surfactant system is a combination of immunomodulatory proteins (5-10\%), phospholipids (PL, 80-85\%) and some other lipids (5$10 \%$ ). Different classes of PL in lung surfactant are PC, PI, PG, PE and SPM. [152,153] (Rau et al., 2004). Phosphatidylcholine (PC) forms the main component of PLs, while Dipalmitoyl-PC (DPPC) shares for about 50\% of PC content performing main role in reducing surface tension. By $35^{\text {th }}$ week of gestation, the levels of Phosphatidylglycerol (PG) reach at peak and can be used as indicator of lung maturation [154]. By this time levels of Phosphatidylinositol are also high but decreases as term approaches hence can be utilized as marker of pulmonary immaturity [154].

Protein composition of surfactant system including surfactant proteins and surface active lipid associated transporter, ABCA3, is of utmost important for both surface activity and immunological homeostasis $[155,156]$. The surfactant proteins are categorized according to their water affinity, in 4 major divisions, SP-A, SP-B, SP-C and SP-D [157] all of which are formed by alveolar type-II cells [152,153,158-167]. The Hydrophobic Surfactant proteins include SP-B and SP-C. SP-B are the surfactant proteins indispensable for survival due to their major role in lowering surface tension by interacting with surfactant PLs [157,168,169] with additional function of forming tubular myelin and packing Phospholipids into lamellar bodies [170] SP-C is the most hydrophobic small protein which also interacts with PLs to lower Surface tension [170].

The hydrophilic surfactant proteins belonging to collectin family are SP-A and SP-D which predominantly chip in in innate immune resistance of respiratory system.[155] both share a structural similarity of possessing $\mathrm{N}$-terminal, a domain, neck region and the Carbohydrate recognition domain (CRD). SP-A is also most abundant protein while SP-D is most hydrophilic in nature [151-155, 158-167, 171-174].

\subsection{Functions of Lung Surfactants}

The increased surface pressure at level of small alveoli has potential to rupture them during expiration $[149,150,175]$. Presence of surfactants lowers the elevated pressure and ensures alveolar integrity during respiratory series and increase lung compliance. Furthermore the ability of surfactant system to counter hydrostatic forces in preventing fluid buildup and edema has also been established [149,150,175,176].

\subsection{Role in Immune Defense}

The hydrophilic class of surfactant proteins contributes the function of host defense in lungs [155,177]. The immune cells that perform the function of pathogen termination include neutrophils, macrophages, DCs and monocytes. SP-A and SP-D can function at different stages of immune response. They can 1) modify the release of inflammatory mediators $[155,178]$. 2) being the 
member of collectin protein family, these surfactant proteins can opsonize various allergens and pathogens through CRD site [179,180]. 3) Ligand-activation of Immune cells [155]. 4) Direct microbicidal activity for pathogens [155,178]. 5) Increase activity of pathogen recognizing cells [181]. 6) Accelerates the activity of macrophages for Phagocytosis of apoptotic cells and in turn promotes the anti-inflammatory response of macrophages [182,183]. SP-A and SP-D are known to specifically modulate the intensities of inflammatory mediators in utero that involve preterm birth [184,185] and acute respiratory distress syndrome [186].

Although the main function of Lung surfactants is to regulate the pressure differential throughout the respiratory cycle, yet research has shown that the role they play in immune defense is not trivial. The surfactant system creates a hitch for invasion of pathogenic organisms [181]. It has ability to camouflage the antigen recognizing receptors in airways, and thus prevent the potential allergen recognition [181]. An important mode of defense to an otherwise inevitable response (bronchoconstriction) of aeroallergen is the capability of surfactants (endogenous/exogenous) to produce bronchodilation, by relaxing smooth muscles of airways [181] and clearing mucociliary secretions [187]. The role of surfactant PLs is observed to be an inhibitor of immune cell responses [188]. They down regulate the release of pro-inflammatory cytokines, signal transduction by Lselectin and activation of nuclear factor-kappa $[153,189]$. In the process of the macrophage induced IIA secretory phospholipase A2 synthesis, Phosphatidylglycerol and surfactant protein-A act as inhibitor [190]. Surfactant PLs also suppress immune response by blocking the synthesis of cytotoxic Oxygen intermediates by macrophages and neutrophils [191]. Though a developed surfactant system warrants the defense of pulmonary system against alveolar collapse and allergic extortions, there is yet another facet of allergy-surfactant relationship which can't be overlooked. In spite of being an important legionnaire of lung defense, surfactant itself is prone to degradation under effect of various inflammatory products such as reactive oxygen species, proteases and phospholipases $[141,192,193]$. This humiliation of surfactant in a developing respiratory system, in response to an ongoing inflammatory response can contribute subsequent pathophysiology of various lung defects.

The current knowledge about lung surfactant system and associated transcriptional guiding modules controlling gene expression for surfactant production and immunity cadence, reveals the multiple functions of surfactants and an insight to number of diseases caused by their abnormalities [156]. Each area requires a great deal of discussion that will be beyond scope of this article. On basis of epidemiological data [194,195], we will restrict our discussion to a brief overview of most prevailing allergic respiratory disorder of respiratory tract "allergic asthma" in context of surfactant abnormalities seeded during fetal, neonatal or early childhood growth period.

\section{Allergic Asthma and Lung Surfactant System}

There are numerous allergic conditions that involve lung, amongst which, Allergic Asthma (AA) is the most prevailing and comprehensively studied disease of early childhood and adults [195,196]. AA is a reversible airway obstruction characterized by bronchospasm, hyperresponsiveness, excessive mucus secretions, remodeling of bronchial wall and decline in respiratory function due to airway inflammation [197-200]. The initial phase of asthma is characterized by IgE mediated release of histamine, cytokines, leukotrines and interleukins (IL-4, 5)

In the fetal and early perinatal period of life, the principal defense against allergic challenges is provided via innate immunity. Research has shown that IgE which starts to develop from $11^{\text {th }}$ week of gestation [110], is capable to contribute in any innate immune response as a sequence of allergen exposure. Furthermore, the immature respiratory system is already sensitive towards exogenous and endogenous vulnerabilities. This fact along with various studies reflects the latent chances of initiating early age allergic asthma in embryonic life and even in neonatal period [201,202].

The role of surfactant abnormality in instigating early origin of asthma has undergone an ardent investigation by many researchers [203-210] The predisposition to allergic coercions is known to increase in surfactant deficiency. This may occur through decreased respiratory compliance, fluid accumulation and edema of airways, diminishing mucociliary clearance, decreased masking of irritant receptors in bronchi and increased exposure to allergens, altered immunological responses and unopposed bronchoconstriction. These alterations are mainly caused by generation of eosinophilic inflammatory substances [211] causing increased degradation of surfactant molecules [209,212] and generation of protein infiltrates in bronchi [205,206,207]. The use of Surfactant Replacement therapy in allergic asthma has shown improved respiratory compliance [213,214] since the advent of synthetic and natural lung surfactants, Surfactant Replacement Therapy is included in protocols for neonates with NRDS and preterm births [108,215]. The surfactant replacement therapy is usually recommended for preterm neonates especially of less than 27 week gestational age and it has established clinical outcomes by improving SPs production [216]. The selection of surfactant therapy depends on severity of respiratory distress syndrome in more mature infants. Another approach to fight against surfactant deficiency is antenatal use of corticosteroids mainly Betamethasone and Dexamethasone. But there is insufficient evidence to show safety vs efficacy profile of steroid use for mother and the fetus $[109,217]$.

\section{Conclusion}

The advent of "Molecular Embryology" has set a prospect of comprehensive knowledge about developmental programming of pulmonary system in fetal and postnatal life. The succeeding awareness has ascertained the involvement of multiple maternal/fetal endogenous or completely exogenous factors in the complex process regulating fetal lung development. A deep learning through literature till day can provide a 
sound insight to physiology and morphology of lung development, yet the important prerequisite for a complete understanding to morphogenesis, growth regulation through multiple factors and transcription dynamics needs a deal of research on the progenitor cell biology of the lung. Many gaps still remain to be filled in understanding all the cellular and molecular mechanisms that lead to differentiation of multipotent progenitor cells, morphogenesis and vasculogenesis. This unleashed knowledge has potential to provide a great insight and solutions to the underline causes of respiratory disorders and congenital lung anomalies.

The advances in understanding of antenatal immune development have established the extensive role of lung surfactant system in providing resistance against pathogens and inhaled allergens. This system works in conjunction with other immunomodulators (pulmonary microphages, DCs, basophils, epithelial cells and cytokines). Both of the two major components of lung surfactant, Surfactant proteins (SP-A, SP-D) and Surfactant Phospholipids (sPL), take part in host defense mechanism. Dominance of IgE based immunity in fetal and early neonatal life has presented the evidence for contribution of surfactant abnormalities in pathophysiology of AA and its prevalence in early life, dominantly in preterm births. Lung surfactant based manipulation of immune responses has potential to target AA and CLD. Thus lung surfactants have dual role in providing defense as well as management of allergic asthma. However many underline molecular mechanisms contributing net responses are yet poorly understood. The future perspective of most efficient and safe clinical interventions lies in exhaustive research in molecular origins of lung biology.

\section{References}

[1] Warburton, D., et al., Lung organogenesis. Curr Top Dev Biol, 2010. 90: p. 73-158.

[2] Greenough, A., Does low birth weight confer a lifelong respiratory disadvantage? Am J Respir Crit Care Med, 2009. 180(2): p. 107-8.

[3] Harding, R., Sustained alterations in postnatal respiratory function following sub-optimal intrauterine conditions. Reprod Fertil Dev, 1995. 7(3): p. 431-41.

[4] Barker, D.J.P., in Mothers, Babies, and Health in Later Life. 1998, Churchill Livingstone.

[5] Jackson, B., et al., Examining the influence of early life socioeconomic position on pulmonary function across the life span: where do we go from here? Thorax, 2004. 59(3): p. 186-8.

[6] Hanrahan, J.P., et al., The effect of maternal smoking during pregnancy on early infant lung function. Am Rev Respir Dis, 1992. 145(5): p. 1129-35.

[7] Gern, J.E., Viral and bacterial infections in the development and progression of asthma. J Allergy Clin Immunol, 2000. 105(2 Pt 2): p. S497-502.

[8] Gern, J.E., et al., Effects of viral respiratory infections on lung development and childhood asthma. J Allergy Clin Immunol, 2005. 115(4): p. 668-74; quiz 675.

[9] Jackson, B., et al., A matter of life and breath: childhood socioeconomic status is related to young adult pulmonary function in the CARDIA study. Int J Epidemiol, 2004. 33(2): p. 271-8.

[10] O'Connor, G.T., et al., The effect of passive smoking on pulmonary function and nonspecific bronchial responsiveness in a population-based sample of children and young adults. Am Rev Respir Dis, 1987. 135(4): p. 800-4.

[11] Shaheen, S., The beginnings of chronic airflow obstruction. Br Med Bull, 1997. 53(1): p. 58-70.
[12] Cliver, S.P., et al., The effect of cigarette smoking on neonatal anthropometric measurements. Obstet Gynecol, 1995. 85(4): p. 625-30.

[13] Kotecha, S., Lung growth: implications for the newborn infant. Arch Dis Child Fetal Neonatal Ed, 2000. 82(1): p. F69-74.

[14] Burri, P.H., Structural aspects of postnatal lung development alveolar formation and growth. Biol Neonate, 2006. 89(4): p. 31322.

[15] Weibel ER, B.P.e., in The Lung: Scientific Foundations. 1997, Lipincott-Raven: Philadelphia.

[16] Ten Have-Opbroek, A.A., The development of the lung in mammals: an analysis of concepts and findings. Am J Anat, 1981. 162(3): p. 201-19.

[17] Ten Have-Opbroek, A.A., J.A. Dubbeldam, and C.J. OttoVerberne, Ultrastructural features of type II alveolar epithelial cells in early embryonic mouse lung. Anat Rec, 1988. 221(4): p. 846-53.

[18] Otto-Verberne, C.J. and A.A. Ten Have-Opbroek, Development of the pulmonary acinus in fetal rat lung: a study based on an antiserum recognizing surfactant-associated proteins. Anat Embryol (Berl), 1987. 175(3): p. 365-73.

[19] Ten Have-Opbroek, A.A. and C.G. Plopper, Morphogenetic and functional activity of type II cells in early fetal rhesus monkey lungs. A comparison between primates and rodents. Anat Rec, 1992. 234(1): p. 93-104.

[20] Langston, C., et al., Human lung growth in late gestation and in the neonate. Am Rev Respir Dis, 1984. 129(4): p. 607-13.

[21] Thurlbeck, W.M., Postnatal human lung growth. Thorax, 1982. 37(8): p. 564-71.

[22] Zorn, A.M. and J.M. Wells, Vertebrate endoderm development and organ formation. Annu Rev Cell Dev Biol, 2009. 25: p. 22151.

[23] Merkus, P.J., A.A. ten Have-Opbroek, and P.H. Quanjer, Human lung growth: a review. Pediatr Pulmonol, 1996. 21(6): p. 383-97.

[24] Metzger, R.J., et al., The branching programme of mouse lung development. Nature, 2008. 453(7196): p. 745-50.

[25] Wessells, N.K., Mammalian lung development: Interactions in formation and morphogenesis of tracheal buds. J. Exp. Zool, 1970. 175(4): p. 455-466.

[26] Spooner, B.S. and N.K. Wessells, Mammalian lung development: interactions in primordium formation and bronchial morphogenesis. J Exp Zool, 1970. 175(4): p. 445-54.

[27] Post, M., Tissue interactions, in The Lung: Scientific Foundations, W.J. Crystal RG, Barnes PJ,, Editor. 1997, Raven Press: New York. p. 1003-1010.

[28] Warburton, D., et al., Molecular embryology and the study of lung development. Am J Respir Cell Mol Biol, 1993. 9(1): p. 5-9.

[29] Thurlbeck, W.M., Postnatal growth and development of the lung. Am Rev Respir Dis, 1975. 111(6): p. 803-44.

[30] Adamson, I.Y. and G.M. King, Epithelial-mesenchymal interactions in postnatal rat lung growth. Exp Lung Res, 1985. 8(4): p. 261-74.

[31] Spooner, B.S. and J.M. Faubion, Collagen involvement in branching morphogenesis of embryonic lung and salivary gland. Dev Biol, 1980. 77(1): p. 84-102.

[32] Larson, J.E., Developmental control of collagen gene expression in the rat lung: confirmation of early observations of lung growth. Pediatr Pulmonol, 1993. 15(4): p. 205-8.

[33] Burri, P.H., Lung development and pulmonary angiogenesis, in Lung Development, B.J. Gaulter C, Post M, Editor. 1999, Oxford University Press: New York. p. 122-151.

[34] Hislop, A.A., Fetal and postnatal anatomical lung development, in Neonatal Respiratory Disorders, A.a.M. Greenough, AD,, Editor. 2003, Arnold:: London. p. 3-11.

[35] Thurlbeck, W.M., Pre-and postnatal organ development, in Basic mechanisms of respiratory disease: Cellular and integrative, M.R. Chernick J, Editor. 1991, BC Decker: Philadelphia. p. 23-35.

[36] Adamson, I., Development of lung structure, in The Lung: Scientific Foundations, W.J. Crystal RG, Barnes PJ, Editor. 1991, Raven Press: New York. p. 993-1001.

[37] Hilfer, S.R., Morphogenesis of the lung: control of embryonic and fetal branching. Annu Rev Physiol, 1996. 58: p. 93-113.

[38] Keeling, J., T.Y. Khong, and S. Gould, The Respiratory System, in Fetal and Neonatal Pathology. 2007, Springer London. p. 531-570.

[39] McDougall, J. and J.F. Smith, The development of the human type II pneumocyte. J Pathol, 1975. 115(4): p. 245-51. 
[40] MacDonald, J., Lung growth and development. . Vol. 13. 1997, New York: Marcel Decker.

[41] Warburton, D., et al., The molecular basis of lung morphogenesis Mech Dev, 2000. 92(1): p. 55-81.

[42] Olver, R.E. and L.B. Strang, Ion fluxes across the pulmonary epithelium and the secretion of lung liquid in the foetal lamb. J Physiol, 1974. 241(2): p. 327-57.

[43] Brown, M.J., et al., Effects of adrenaline and of spontaneous labour on the secretion and absorption of lung liquid in the fetal lamb. J Physiol, 1983. 344: p. 137-52.

[44] Frank, L. and I.R. Sosenko, Failure of premature rabbits to increase antioxidant enzymes during hyperoxic exposure: increased susceptibility to pulmonary oxygen toxicity compared with term rabbits. Pediatr Res, 1991. 29(3): p. 292-6.

[45] Maeda, Y., V. Dave, and J.A. Whitsett, Transcriptional control of lung morphogenesis. Physiol Rev, 2007. 87(1): p. 219-44.

[46] Zorn, A.M. and J.M. Wells, Molecular basis of vertebrate endoderm development. Int Rev Cytol, 2007. 259: p. 49-111.

[47] Morrisey, E.E. and B.L. Hogan, Preparing for the first breath: genetic and cellular mechanisms in lung development. Dev Cell, 2010. 18(1): p. 8-23.

[48] Gang Chen, H.W., Fengming Luo, Liqian Zhang, Yan Xu, and M.W.-K. Ian Lewkowich, and Jeffrey A. Whitsett, Foxa2 Programs Th2 Cell-Mediated Innate Immunity in the Developing Lung. The Journal of Immunology, 2010. 184: p. 6133-6141.

[49] Chen, F., et al., Inhibition of Tgf beta signaling by endogenous retinoic acid is essential for primary lung bud induction. Development, 2007. 134(16): p. 2969-79.

[50] Cardoso, W.V. and J. Lu, Regulation of early lung morphogenesis: questions, facts and controversies. Development, 2006. 133(9): p. 1611-24.

[51] Mailleux, A.A., et al., Evidence that SPROUTY2 functions as an inhibitor of mouse embryonic lung growth and morphogenesis. Mech Dev, 2001. 102(1-2): p. 81-94.

[52] Bostrom, H., et al., PDGF-A signaling is a critical event in lung alveolar myofibroblast development and alveogenesis. Cell, 1996. 85(6): p. 863-73.

[53] Weinstein, M., et al., FGFR-3 and FGFR-4 function cooperatively to direct alveogenesis in the murine lung. Development, 1998. 125(18): p. 3615-23.

[54] Shannon, J.M. and B.A. Hyatt, Epithelial-mesenchymal interactions in the developing lung. Annu Rev Physiol, 2004. 66: p. $625-45$.

[55] Flamme, I., G. Breier, and W. Risau, Vascular endothelial growth factor (VEGF) and VEGF receptor 2 (flk-1) are expressed during vasculogenesis and vascular differentiation in the quail embryo. Dev Biol, 1995. 169(2): p. 699-712.

[56] Flamme, I., et al., Overexpression of vascular endothelial growth factor in the avian embryo induces hypervascularization and increased vascular permeability without alterations of embryonic pattern formation. Dev Biol, 1995. 171(2): p. 399-414.

[57] Gebb, S.A. and J.M. Shannon, Tissue interactions mediate early events in pulmonary vasculogenesis. Dev Dyn, 2000. 217(2): p. 159-69.

[58] Yamaguchi, T.P., et al., flk-1, an flt-related receptor tyrosine kinase is an early marker for endothelial cell precursors. Development, 1993. 118(2): p. 489-98.

[59] Drake, C.J. and C.D. Little, Exogenous vascular endothelial growth factor induces malformed and hyperfused vessels during embryonic neovascularization. Proc Natl Acad Sci U S A, 1995. 92(17): p. 7657-61.

[60] Baldwin, H.S., Early embryonic vascular development. Cardiovasc Res, 1996. 31 Spec No: p. E34-45.

[61] Zhao, L., et al., Vascular endothelial growth factor co-ordinates proper development of lung epithelium and vasculature. Mech Dev, 2005. 122(7-8): p. 877-86.

[62] Schittny, J.C., et al., Programmed cell death contributes to postnatal lung development. Am J Respir Cell Mol Biol, 1998. 18(6): p. 786-93.

[63] Sasaki, H. and B.L. Hogan, HNF-3 beta as a regulator of floor plate development. Cell, 1994. 76(1): p. 103-15.

[64] Thebaud, B., Update in Pediatric Lung Disease. Am J Respir Crit Care Med, 2011. 183: p. 1477-1481.

[65] Attar, M.A. and S. Sarkar, Developmental Lung Anomalies, in Manual of Neonatal Respiratory Care, S.M. Donn and S.K. Sinha, Editors. 2012, Springer. p. 17.
[66] Gabbi Parker, H.V., Management of upper airway obstruction in children. Paediatrics and Child Health, 2009. 19(6): p. 276-281.

[67] Maritz, G.S., C.J. Morley, and R. Harding, Early developmental origins of impaired lung structure and function. Early Human Development, 2005. 81(9): p. 763-771.

[68] Groenman, F., S. Unger, and M. Post, The molecular basis for abnormal human lung development. Neonatology, 2005. 87(3): p. 164-177.

[69] Kassner, E.G., et al., Pulmonary candidiasis in infants: clinical, radiologic, and pathologic features. AJR Am J Roentgenol, 1981. 137(4): p. 707-16.

[70] Keller, M.A., et al., Systemic candidiasis in infants: a case presentation and literature review. Am J Dis Child, 1977. 131(11): p. 1260-3.

[71] Gravett, M.G., et al., Independent associations of bacterial vaginosis and Chlamydia trachomatis infection with adverse pregnancy outcome. JAMA, 1986. 256(14): p. 1899-903.

[72] Lamont, R.F., et al., The role of mycoplasmas, ureaplasmas and chlamydiae in the genital tract of women presenting in spontaneous early preterm labour. J Med Microbiol, 1987. 24(3): p. 253-7.

[73] Cassell, G.H., et al., Ureaplasma urealyticum intrauterine infection role in prematurity and disease in newborns. Clin Microbiol Rev, 1993. 6(1): p. 69-87.

[74] Modlin, J.F., Perinatal echovirus infection: insights from a literature review of 61 cases of serious infection and 16 outbreaks in nurseries. Rev Infect Dis, 1986. 8(6): p. 918-26.

[75] Abzug, M.J., et al., Viral pneumonia in the first month of life. Pediatr Infect Dis J, 1990. 9(12): p. 881-5.

[76] Northway, W.H., Jr., R.C. Rosan, and D.Y. Porter, Pulmonary disease following respirator therapy of hyaline-membrane disease. Bronchopulmonary dysplasia. N Engl J Med, 1967. 276(7): p. 357-68.

[77] Jobe, A.H., Antenatal factors and the development of bronchopulmonary dysplasia. Semin Neonatol, 2003. 8(1): p. 9-17.

[78] Jobe, A.H. and E. Bancalari, Bronchopulmonary dysplasia. Am J Respir Crit Care Med, 2001. 163(7): p. 1723-9.

[79] Harding, R., et al., The compromised intra-uterine environment: implications for future lung health. Clin Exp Pharmacol Physiol, 2000. 27(12): p. 965-74.

[80] Hooper, S.B. and R. Harding, Fetal lung liquid: a major determinant of the growth and functional development of the fetal lung. Clin Exp Pharmacol Physiol, 1995. 22(4): p. 235-47.

[81] Wilson, S.M., R.E. Olver, and D.V. Walters, Developmental regulation of lumenal lung fluid and electrolyte transport. Respir Physiol Neurobiol, 2007. 159(3): p. 247-55.

[82] Alcorn, D., et al., Morphological effects of chronic tracheal ligation and drainage in the fetal lamb lung. J Anat, 1977. 123(Pt 3): p. 649-60.

[83] Moessinger, A.C., et al., Role of lung fluid volume in growth and maturation of the fetal sheep lung. J Clin Invest, 1990. 86(4): p. 1270-7.

[84] Wigglesworth, J.S. and R. Desai, Is fetal respiratory function a major determinant of perinatal survival? Lancet, 1982. 1(8266): p. 264-7.

[85] Sahebjami, H., Nutrition and lung structure and function. Exp Lung Res, 1993. 19(2): p. 105-24.

[86] Kalenga M, G.C., Burri P. H, Nutritional aspects of lung development., in Lung Development, B.J. Gaultier C, Post M, Editor. 1999, Oxford University Press: New York. p. 347-63.

[87] Curle, D.C. and I.Y. Adamson, Retarded development of noenatal rat lung by maternal malnutrition. J Histochem Cytochem, 1978. 26(5): p. 401-8.

[88] Lin, Y. and A.J. Lechner, Surfactant content and type II cell development in fetal guinea pig lungs during prenatal starvation. Pediatr Res, 1991. 29(3): p. 288-91.

[89] Faridy, E.E., Effect of maternal malnutrition on surface activity of fetal lungs in rats. J Appl Physiol, 1975. 39(4): p. 535-40.

[90] Winick, M. and A. Noble, Cellular response in rats during malnutrition at various ages. J Nutr, 1966. 89(3): p. 300-6.

[91] Sahebjami, H. and J. MacGee, Effects of starvation on lung mechanics and biochemistry in young and old rats. J Appl Physiol, 1985. 58(3): p. 778-84.

[92] Das, R.M., The effects of intermittent starvation on lung development in suckling rats. Am J Pathol, 1984. 117(2): p. 32632. 
[93] Liu, M., A.K. Tanswell, and M. Post, Mechanical force-induced signal transduction in lung cells. Am J Physiol, 1999. 277(4 Pt 1): p. L667-83.

[94] Lechner, A.J., D.C. Winston, and J.E. Bauman, Lung mechanics, cellularity, and surfactant after prenatal starvation in guinea pigs. $\mathrm{J}$ Appl Physiol, 1986. 60(5): p. 1610-4.

[95] Massaro, D., et al., Postnatal development of alveoli. Regulation and evidence for a critical period in rats. J Clin Invest, 1985. 76(4): p. 1297-305.

[96] Bellanti, J.A., B.J. Zeligs, and L.L. Kulszycki, Nutrition and development of pulmonary defense mechanisms. Pediatr Pulmonol Suppl, 1997. 16: p. 170-1.

[97] Morsing, E., P. Gustafsson, and J. Brodszki, Lung function in children born after foetal growth restriction and very preterm birth. Acta Paediatr, 2012. 101(1): p. 48-54.

[98] Larson, J.E. and W.M. Thurlbeck, The effect of experimental maternal hypoxia on fetal lung growth. Pediatr Res, 1988. 24(2): p. 156-9.

[99] Jacobs, R., et al., The effect of prolonged hypobaric hypoxia on growth of fetal sheep. J Dev Physiol, 1988. 10(2): p. 97-112.

[100] Gortner, L., et al., Hypoxia-induced intrauterine growth retardation: effects on pulmonary development and surfactant protein transcription. Biol Neonate, 2005. 88(2): p. 129-35.

[101] Prabhakar, N.R. and G.L. Semenza, Adaptive and Maladaptive Cardiorespiratory Responses to Continuous and Intermittent Hypoxia Mediated by Hypoxia-Inducible Factors 1 and 2. Physiological Reviews, 2012. 92(3): p. 967-1003.

[102] Groenman, F., et al., Hypoxia-inducible factors in the first trimester human lung. Journal of Histochemistry \& Cytochemistry, 2007. 55(4): p. 355-363.

[103] Patel, S.A. and M.C. Simon, Biology of hypoxia-inducible factor$2 \hat{\mathrm{I}} \pm$ in development and disease. Cell Death \& Differentiation, 2008. 15(4): p. 628-634.

[104] Boland, R., et al., Cortisol enhances structural maturation of the hypoplastic fetal lung in sheep. J Physiol, 2004. 554(Pt 2): p. 50517.

[105] Jones, M.B., Respiratory distress syndrome and the induction of fetal lung maturity by the use of glucocorticoids. JOGN Nurs, 1977. 6(4): p. 21-8

[106] Riley, C.A., K. Boozer, and T.L. King, Antenatal corticosteroids at the beginning of the 21 st century. J Midwifery Womens Health, 2011. 56(6): p. 591-7.

[107] Holsapple, M.P., L.J. West, and K.S. Landreth, Species comparison of anatomical and functional immune system development. Birth Defects Res B Dev Reprod Toxicol, 2003. 68(4): p. 321-34.

[108] Rona, R.J., M.C. Gulliford, and S. Chinn, Effects of prematurity and intrauterine growth on respiratory health and lung function in childhood. BMJ, 1993. 306(6881): p. 817-20.

[109] Wapner, R. and A.H. Jobe, Controversy: Antenatal Steroids. Clinics in Perinatology, 2011. 38(3): p. 529-545.

[110] Lambrecht, B.N. and H. Hammad, Biology of lung dendritic cells at the origin of asthma. Immunity, 2009. 31(3): p. 412-24.

[111] Leibnitz, R., Development of the human immune system, in Developmental immunotoxicology, H. SD., Editor. 2005, CRC Press: Boca Raton. p. 21-42.

[112] Abraham, C.M. and D.R. Ownby, Ontogeny of the allergic inflammatory response. Immunol Allergy Clin North Am, 2005 25(2): p. 215-29, v

[113] Holt, P.G., J.W. Upham, and P.D. Sly, Contemporaneous maturation of immunologic and respiratory functions during early childhood: implications for development of asthma prevention strategies. J Allergy Clin Immunol, 2005. 116(1): p. 16-24; quiz 25 .

[114] Diamond, G., D. Legarda, and L.K. Ryan, The innate immune response of the respiratory epithelium. Immunol Rev, 2000. 173: p. 27-38.

[115] Schulz, C., et al., Differences in LPS-induced activation of bronchial epithelial cells (BEAS-2B) and type II-like pneumocytes (A-549). Scand J Immunol, 2002. 56(3): p. 294-302.

[116] Hou, Y.F., et al., Modulation of expression and function of Tolllike receptor 3 in A549 and H292 cells by histamine. Mol Immunol, 2006. 43(12): p. 1982-92

[117] Hewson, C.A., et al., Toll-like receptor 3 is induced by and mediates antiviral activity against rhinovirus infection of human bronchial epithelial cells. J Virol, 2005. 79(19): p. 12273-9.
[118] Vogt-Eisele, A.K., et al., Monoterpenoid agonists of TRPV3. Br J Pharmacol, 2007. 151(4): p. 530-40.

[119] Sherkheli, M.A., et al., Characterization of selective TRPM8 ligands and their structure activity response (S.A.R) relationship. J Pharm Pharm Sci, 2010. 13(2): p. 242-53.

[120] Sherkheli, M.A., et al., Monoterpenoids induce agonist-specific desensitization of transient receptor potential vanilloid-3 (TRPV3) ion channels. J Pharm Pharm Sci, 2009. 12(1): p. 116-28.

[121] Sherkheli, M.A., et al., Menthol derivative WS-12 selectively activates transient receptor potential melastatin-8 (TRPM8) ion channels. Pak J Pharm Sci, 2008. 21(4): p. 370-8.

[122] Sherkheli, M.A., Gisselmann G. and Hatt H., Supercooling Agent Icilin Blocks a Warmth-Sensing Ion Channel TRPV3. The Scientific World Journal, 2012. 2012.

[123] Preti, D., A. Szallasi, and R. Patacchini, TRP channels as therapeutic targets in airway disorders: a patent review. Expert Opin Ther Pat, 2012. 22(6): p. 663-95

[124] Gosling, M., C. Poll, and S. Li, TRP channels in airway smooth muscle as therapeutic targets. Naunyn Schmiedebergs Arch Pharmacol, 2005. 371(4): p. 277-84.

[125] Sha, Q., et al., Activation of airway epithelial cells by toll-like receptor agonists. Am J Respir Cell Mol Biol, 2004. 31(3): p. 35864

[126] Muir, A., et al., Toll-like receptors in normal and cystic fibrosis airway epithelial cells. Am J Respir Cell Mol Biol, 2004. 30(6): p. 777-83.

[127] 127. Oshikawa, K. and Y. Sugiyama, Regulation of toll-like receptor 2 and 4 gene expression in murine alveolar macrophages. Exp Lung Res, 2003. 29(6): p. 401-12.

[128] Holt, P.G., Programming for responsiveness to environmental antigens that trigger allergic respiratory disease in adulthood is initiated during the perinatal period. Environ Health Perspect, 1998. 106 Suppl 3: p. 795-800

[129] Reynolds, H.Y., Lung inflammation and fibrosis: an alveolar macrophage-centered perspective from the 1970s to 1980s. Am J Respir Crit Care Med, 2005. 171(2): p. 98-102.

[130] Fels, A.O. and Z.A. Cohn, The alveolar macrophage. J Appl Physiol, 1986. 60(2): p. 353-69.

[131] Mosmann, T.R. and S. Sad, The expanding universe of T-cell subsets: Th1, Th2 and more. Immunol Today, 1996. 17(3): p. 13846.

[132] Robinson, D.S., et al., Predominant TH2-like bronchoalveolar Tlymphocyte population in atopic asthma. N Engl J Med, 1992. 326(5): p. 298-304.

[133] Devereux, G., R.N. Barker, and A. Seaton, Antenatal determinants of neonatal immune responses to allergens. Clin Exp Allergy, 2002. 32(1): p. 43-50.

[134] Devereux, G., A. Seaton, and R.N. Barker, In utero priming of allergen-specific helper T cells. Clin Exp Allergy, 2001. 31(11): p. 1686-95.

[135] Liao, S.Y., et al., Decreased production of IFN gamma and increased production of IL-6 by cord blood mononuclear cells of newborns with a high risk of allergy. Clin Exp Allergy, 1996. 26(4): p. 397-405

[136] Miles, E.A., et al., Peripheral blood mononuclear cell proliferative responses in the first year of life in babies born to allergic parents. Clin Exp Allergy, 1996. 26(7): p. 780-8.

[137] Prescott, S.L., et al., Transplacental priming of the human immune system to environmental allergens: universal skewing of initial $\mathrm{T}$ cell responses toward the Th2 cytokine profile. J Immunol, 1998. 160(10): p. 4730-7.

[138] Tang, M.L., et al., Reduced interferon-gamma secretion in neonates and subsequent atopy. Lancet, 1994. 344(8928): p. 983-5

[139] Gold, D.R. and R. Wright, Population disparities in asthma. Annu Rev Public Health, 2005. 26: p. 89-113.

[140] Pinkerton, K.E. and J.P. Joad, Influence of air pollution on respiratory health during perinatal development. Clin Exp Pharmacol Physiol, 2006. 33(3): p. 269-72.

[141] Sly, R.M., Changing prevalence of allergic rhinitis and asthma. Ann Allergy Asthma Immunol, 1999. 82(3): p. 233-48; quiz 24852 .

[142] Hamada, K., et al., Exposure of pregnant mice to an air pollutant aerosol increases asthma susceptibility in offspring. J Toxicol Environ Health A, 2007. 70(8): p. 688-95.

[143] Jones, C.A., J.A. Holloway, and J.O. Warner, Fetal immune responsiveness and routes of allergic sensitization. Pediatr Allergy Immunol, 2002. 13 Suppl 15: p. 19-22. 
[144] Pattle, R.E., Properties, function and origin of the alveolar lining layer. Nature, 1955. 175(4469): p. 1125-6.

[145] Szekers-Bartho, J., Immunological Relationship between the Mother and the Fetus. International Reviews of Immunology, 2002. 21(6): p. 471-495.

[146] Warner, J.A., et al., Prenatal origins of allergic disease. J Allergy Clin Immunol, 2000. 105(2 Pt 2): p. S493-8.

[147] Gon, Y., et al., A20 inhibits toll-like receptor 2- and 4-mediated interleukin-8 synthesis in airway epithelial cells. Am J Respir Cell Mol Biol, 2004. 31(3): p. 330-6.

[148] Holgate, S.T., The epithelium takes centre stage in asthma and atopic dermatitis. Trends Immunol, 2007. 28(6): p. 248-51.

[149] Kuroki, Y. and D.R. Voelker, Pulmonary surfactant proteins. J Biol Chem, 1994. 269(42): p. 25943-6.

[150] Frerking, I., et al., Pulmonary surfactant: functions, abnormalities and therapeutic options. Intensive Care Med, 2001. 27(11): p. 1699-717.

[151] Griese, M., Pulmonary surfactant in health and human lung diseases: state of the art. Eur Respir J, 1999. 13(6): p. 1455-76.

[152] Wright, J.R., Clearance and recycling of pulmonary surfactant. Am J Physiol, 1990. 259(2 Pt 1): p. L1-12.

[153] Field, N.T. and W.M. Gilbert, Current status of amniotic fluid tests of fetal maturity. Clin Obstet Gynecol, 1997. 40(2): p. 366-86.

[154] Bernhard, W., et al., Phosphatidylcholine molecular species in lung surfactant: composition in relation to respiratory rate and lung development. Am J Respir Cell Mol Biol, 2001. 25(6): p. 725-31.

[155] Tokieda, K., et al., Pulmonary dysfunction in neonatal SP-Bdeficient mice. Am J Physiol, 1997. 273(4 Pt 1): p. L875-82.

[156] Whitsett, J.A., Review: The intersection of surfactant homeostasis and innate host defense of the lung: lessons from newborn infants. Innate Immunity, 2010. 16(3): p. 138-142.

[157] Izzo, C. and P.P. Rickham, Neonatal pulmonary hamartoma. Journal of Pediatric Surgery, 1968. 3(1, Part 1): p. 77-83.

[158] Hobo, S., et al., Effect of transportation on the composition of bronchoalveolar lavage fluid obtained from horses. Am J Vet Res, 1997. 58(5): p. 531-4.

[159] Hobo, S., et al., Surfactant proteins in bronchoalveolar lavage fluid of horses: assay technique and changes following road transport. Vet Rec, 2001. 148(3): p. 74-80.

[160] Ito, S., S. Hobo, and Y. Kasashima, Bronchoalveolar lavage fluid findings in the atelectatic regions of anesthetized horses. J Vet Med Sci, 2003. 65(9): p. 1011-3.

[161] Morrison, K.E., et al., Functional and compositional changes in pulmonary surfactant in response to exercise. Equine Vet J Suppl, 1999. 30: p. 62-6.

[162] Danlois, F., et al., Pulmonary surfactant from healthy Belgian White and Blue and Holstein Friesian calves: biochemical and biophysical comparison. Vet J, 2003. 165(1): p. 65-72.

[163] Christmann, U., et al., Abnormalities in lung surfactant in horses clinically affected with recurrent airway obstruction (RAO). J Vet Intern Med, 2008. 22(6): p. 1452-5.

[164] Danlois, F., et al., Very low surfactant protein C contents in newborn Belgian White and Blue calves with respiratory distress syndrome. Biochem J, 2000. 351 Pt 3: p. 779-87.

[165] Bernhard, W., et al., Conductive airway surfactant: surface-tension function, biochemical composition, and possible alveolar origin. Am J Respir Cell Mol Biol, 1997. 17(1): p. 41-50.

[166] Wright, J.R., Immunoregulatory functions of surfactant proteins. Nat Rev Immunol, 2005. 5(1): p. 58-68.

[167] Weaver, T.E. and J.J. Conkright, Function of surfactant proteins B and C. Annu Rev Physiol, 2001. 63: p. 555-78.

[168] Whitsett, J.A. and T.E. Weaver, Hydrophobic surfactant proteins in lung function and disease. N Engl J Med, 2002. 347(26): p. 2141-8.

[169] Madsen, J., et al., Localization of lung surfactant protein D on mucosal surfaces in human tissues. J Immunol, 2000. 164(11): p. 5866-70.

[170] Leth-Larsen, R., et al., Surfactant protein D in the female genital tract. Mol Hum Reprod, 2004. 10(3): p. 149-54.

[171] Rau, G.A., et al., Surfactant in newborn compared with adolescent pigs: adaptation to neonatal respiration. Am J Respir Cell Mol Biol, 2004. 30(5): p. 694-701.

[172] Sano, H. and Y. Kuroki, The lung collectins, SP-A and SP-D, modulate pulmonary innate immunity. Mol Immunol, 2005. 42(3): p. $279-87$.
[173] Macklem, P.T., D.F. Proctor, and J.C. Hogg, The stability of peripheral airways. Respir Physiol, 1970. 8(2): p. 191-203.

[174] Notter, R.H., Lung surfactants: basic science and clinical applications, in Lung Biology in Health and Disease, C. L, Editor. 2000, Dekker: New York. p. 207-248.

[175] Enhorning, G., L.C. Duffy, and R.C. Welliver, Pulmonary surfactant maintains patency of conducting airways in the rat. Am J Respir Crit Care Med, 1995. 151(2 Pt 1): p. 554-6.

[176] Meyer, K.C. and J.J. Zimmerman, Inflammation and surfactant. Paediatr Respir Rev, 2002. 3(4): p. 308-14.

[177] Wright, J.R., Host defense functions of pulmonary surfactant. Biol Neonate, 2004. 85(4): p. 326-32.

[178] Wright, J.R., Pulmonary surfactant: a front line of lung host defense. J Clin Invest, 2003. 111(10): p. 1453-5.

[179] Chiba, H., et al., Human surfactant protein D (SP-D) binds Mycoplasma pneumoniae by high affinity interactions with lipids. Journal of Biological Chemistry, 2002. 277(23): p. 20379-20385.

[180] Reidy, M.F. and J.R. Wright, Surfactant protein A enhances apoptotic cell uptake and TGF-beta1 release by inflammatory alveolar macrophages. American journal of physiology. Lung cellular and molecular physiology, 2003. 285(4): p. L854-61.

[181] Matalon, S. and J.R. Wright, Surfactant proteins and inflammation: the yin and the yang. Am J Respir Cell Mol Biol, 2004. 31(6): p. 585-6.

[182] De Sanctis, G.T., et al., Exogenous surfactant enhances mucociliary clearance in the anaesthetized dog. Eur Respir J, 1994 7(9): p. 1616-21.

[183] Baritussio, A., Lung surfactant, asthma, and allergens: a story in evolution. Am J Respir Crit Care Med, 2004. 169(5): p. 550-1.

[184] Annamari Salminen, R.V., Reija Paananen, Marja Ojaniemi, Mikko Hallman, Surfactant protein D modulates levels of IL-10 and TNF- $\alpha$ in intrauterine compartments during lipopolysaccharide-induced preterm birth. Cytokine, 2012. 60(2): p. 423-430.

[185] Annamari Salminen, R.V., Reija Paananen, Marja Ojaniemi, Mikko Hallman, Surfactant protein A modulates the lipopolysaccharide-induced inflammatory response related to preterm birth. Cytokine 2011. 56(2): p. 442-449.

[186] King, B.A. and K. Paul S, Surfactant Protein D Deficiency Increases Lung Injury During Endotoxemia. Am J Respir Cell Mol Biol, 2011. 44: p. 709-715.

[187] Wilsher, M.L., D.A. Hughes, and P.L. Haslam, Immunoregulatory properties of pulmonary surfactant: effect of lung lining fluid on proliferation of human blood lymphocytes. Thorax, 1988. 43(5): p. 354-9.

[188] Chao, W., R.G. Spragg, and R.M. Smith, Inhibitory effect of porcine surfactant on the respiratory burst oxidase in human neutrophils. Attenuation of p47phox and p67phox membrane translocation as the mechanism. J Clin Invest, 1995. 96(6): p. 2654-60.

[189] Wu, Y.Z., et al., Surfactant protein-A and phosphatidylglycerol suppress type IIA phospholipase A2 synthesis via nuclear factorkappaB. Am J Respir Crit Care Med, 2003. 168(6): p. 692-9.

[190] Hirche, T.O., et al., Neutrophil serine proteinases inactivate surfactant protein D by cleaving within a conserved subregion of the carbohydrate recognition domain. J Biol Chem, 2004. 279(26): p. 27688-98.

[191] Ackerman, S.J., et al., Hydrolysis of surfactant phospholipids catalyzed by phospholipase A2 and eosinophil lysophospholipases causes surfactant dysfunction: a mechanism for small airway closure in asthma. Chest, 2003. 123(3 Suppl): p. 355S.

[192] Seeds, M.C., et al., Human eosinophil group IID secretory phospholipase A2 causes surfactant dysfunction. Chest, 2003. 123(3 Suppl): p. 376S-7S.

[193] McSharry, C., et al., Takes your breath away--the immunology of allergic alveolitis. Clin Exp Immunol, 2002. 128(1): p. 3-9.

[194] Hesselmar, B., et al., Asthma in children: prevalence, treatment, and sensitization. Pediatric allergy and immunology, 2002. 11(2): p. 74-79.

[195] Masoli, M., et al., The global burden of asthma: executive summary of the GINA Dissemination Committee report. Allergy, 2004. 59(5): p. 469-78.

[196] Brusasco, V. and R. Pellegrino, Complexity of factors modulating airway narrowing in vivo: relevance to assessment of airway hyperresponsiveness. J Appl Physiol, 2003. 95(3): p. 1305-13.

[197] James, A., Airway remodeling in asthma. Curr Opin Pulm Med, 2005. 11(1): p. 1-6. 
[198] Sears, M.R., Lung function decline in asthma. Eur Respir J, 2007. 30(3): p. 411-3.

[199] Kurashima, K., et al., Surface activity of sputum from acute asthmatic patients. Am J Respir Crit Care Med, 1997. 155(4): p. 1254-9.

[200] Jarjour, N.N. and G. Enhorning, Antigen-induced airway inflammation in atopic subjects generates dysfunction of pulmonary surfactant. Am J Respir Crit Care Med, 1999. 160(1): p. 336-41.

[201] Hohlfeld, J.M., et al., Eosinophil cationic protein alters pulmonary surfactant structure and function in asthma. J Allergy Clin Immunol, 2004. 113(3): p. 496-502.

[202] Singh, M., Infection and Allergy: The Inverse Link. Asthma in Children, 2012: p. 38.

[203] Hohlfeld, J.M., et al., Dysfunction of pulmonary surfactant in asthmatics after segmental allergen challenge. Am J Respir Crit Care Med, 1999. 159(6): p. 1803-9.

[204] Heeley, E.L., et al., Phospholipid molecular species of bronchoalveolar lavage fluid after local allergen challenge in asthma. Am J Physiol Lung Cell Mol Physiol, 2000. 278(2): p. L305-11.

[205] Wright, S.M., et al., Altered airway surfactant phospholipid composition and reduced lung function in asthma. J Appl Physiol, 2000. 89(4): p. 1283-92.

[206] Hite, R.D., et al., Surfactant phospholipid changes after antigen challenge: a role for phosphatidylglycerol in dysfunction. Am J Physiol Lung Cell Mol Physiol, 2005. 288(4): p. L610-7.

[207] Pohunek, P., et al., Markers of eosinophilic inflammation and tissue re-modelling in children before clinically diagnosed bronchial asthma. Pediatr Allergy Immunol, 2005. 16(1): p. 43-51.
[208] Hite, R.D., et al., Lysophospholipid generation and phosphatidylglycerol depletion in phospholipase $\mathrm{A}(2)$-mediated surfactant dysfunction. Am J Physiol Lung Cell Mol Physiol, 2005. 288(4): p. L618-24.

[209] Van Den Toorn, L.M., et al., Airway inflammation is present during clinical remission of atopic asthma. American journal of respiratory and critical care medicine, 2001. 164(11): p. 21072113.

[210] Henderson, A.J. and J.O. Warner. Fetal origins of asthma. in Seminars in Fetal and Neonatal Medicine. 2012: Elsevier.

[211] Babu, K.S., et al., Inhaled synthetic surfactant abolishes the early allergen-induced response in asthma. Eur Respir J, 2003. 21(6): p. 1046-9.

[212] Kurashima, K., et al., A pilot study of surfactant inhalation in the treatment of asthmatic attack. Arerugi, 1991. 40(2): p. 160-3.

[213] Fujiwara, T., et al., Artificial surfactant therapy in hyalinemembrane disease. Lancet, 1980. 1(8159): p. 55-9.

[214] Jobe, A.H., Pulmonary surfactant therapy. N Engl J Med, 1993. 328(12): p. 861-8.

[215] Anand, D., et al., Lung function and respiratory health in adolescents of very low birth weight. Arch Dis Child, 2003. 88(2): p. 135-8.

[216] Bersani, I., C.P. Speer, and S. Kunzmann, Surfactant proteins A and $D$ in pulmonary diseases of preterm infants. Expert Review of Anti-infective Therapy, 2012. 10(5): p. 573-584.

[217] Vyas, J. and S. Kotecha, Effects of antenatal and postnatal corticosteroids on the preterm lung. Arch Dis Child Fetal Neonatal Ed, 1997. 77(2): p. F147-50. 